\title{
Under-Treatment and Poorer Survival Outcomes in Elderly Breast Cancer Patients in Singapore: A Comparison with Younger Patients in a Tertiary Institution
}

\author{
Chi Wei Mok*, Siew Kuan Lim, Su-Ming Tan \\ Division of Breast Surgery, Department of General Surgery, Changi General Hospital, Singapore \\ Email:*mok.chi.wei@singhealth.com.sg
}

How to cite this paper: Mok, C.W., Lim, S.K. and Tan, S.-M. (2018) Under-Treatment and Poorer Survival Outcomes in Elderly Breast Cancer Patients in Singapore: A Comparison with Younger Patients in a Tertiary Institution. Journal of Cancer Therapy, 9, 402-416.

https://doi.org/10.4236/jct.2018.95036

Received: March 10, 2018

Accepted: May 11, 2018

Published: May 14, 2018

Copyright $\odot 2018$ by authors and Scientific Research Publishing Inc. This work is licensed under the Creative Commons Attribution International License (CC BY 4.0). http://creativecommons.org/licenses/by/4.0/

\section{Open Access}

\begin{abstract}
Introduction: The numbers of elderly patients with breast cancers are increasing with an ageing population, yet clinical research on these patients is still lacking. This study aims to examine the differences between elderly patients and their younger counterparts, with a view to optimize management plans for the former. Methods: Patients $\geq 40$ years old with histologically proven breast cancer between 1991 and 2008 were identified from our database, and grouped according to age for analyses: old elderly ( $\geq 75$ years), young elderly (65 to 74 years) and young (40 to 64 years). Clinicopathologic characteristics, treatment and survival rates were compared across the 3 groups. Results: There were 103 (11.53\%) old elderly, 147 (16.5\%) young elderly and $643(72.0 \%)$ young patients. The 2 elderly groups presented at later stages, received less adjuvant or palliative chemotherapy $(\mathrm{P}<0.001)$, and less adjuvant radiotherapy $(\mathrm{P}<0.001)$, compared to the younger patients. Both breast cancer specific survival (CSS) and overall survival (OS) in the old elderly (CSS: 64.7\% (95\% confidence interval [CI]: 53.4\% - 73.8\%), OS: $46.4 \%$ (95\% CI: $35.6 \%-56.4 \%)$ ) and young elderly group (CSS: $82.4 \%$ (95\% CI: $74.4 \%$ - $88.0 \%$ ) OS: $78.6 \%$ (95\% CI: $70.4 \%$ - 84.8\%)) were lower than the young patient group (CSS: $84.9 \%$ (95\% CI: $81.6 \%$ - 87.7\%), OS: $83.4 \%$ (95\% CI: $80.0 \%-86.3 \%)$ ) at 5 years. Conclusion: Our findings showed that clinicopathologic characteristics of elderly breast cancer patients differed from their younger counterparts. Poorer survival outcomes among our elderly patients may be the result of their under-treatment.
\end{abstract}

\section{Keywords}

Elderly, Breast Cancer, Under-Treatment, Survival Outcome 


\section{Introduction}

Breast cancer is the most common female cancer in the vast majority of countries, including Singapore [1] [2] [3] and ageing is one of the single greatest risk factors for the development of new breast cancer [4]. With increasing life expectancies and a rapidly ageing global population [5], more breast cancers are being diagnosed in older women, and this rising trend is expected to continue.

There are several challenges associated with cancer treatment and analyses of survival outcomes in older patients. The first problem is in the very definition of what constitutes the older patient and setting the age limit. Although the National Comprehensive Cancer Centre Network (NCCN) guidelines mark this limit at 65 years, it is mostly from 70 - 75 years when age-related changes appear at different levels (functional, cognitive, physiological, presence of comorbidities and socio-economic status) [6]. Further, heterogeneity in the aging process also adds to the difficulties of defining this age limit [7].

Further, breast cancers in old elderly or young elderly patients differ from those in young patients as the physiological changes triggered by ageing influence the development of malignancies. Studies from Western countries have described more estrogen receptor (ER) positive and fewer human epidermal growth factor receptor 2 (HER2) positive breast cancers in elderly patients, which may suggest less aggressive biology [8] [9] [10] [11]. However, another study using Surveillance, Epidemiology and End Results-Medicare data showed increased nodal involvement in those $\geq 80$ years old, as well as similar breast cancer characteristics (tumour grade, histology, hormone receptivity) between women $\geq 80$ years of age and women aged $67-79$ years [12]. The exclusion of elderly patients from screening programs and their low participation rates in clinical trials in turn result in the absence of a common or standard approach to the treatment of elderly breast cancers [13] [14].

In addition to this, physiological changes also affect tolerance to treatment due to the higher frequency of comorbidities and decline in physiological reserve in marrow and renal function [15]. Managing older cancer patients requires taking into account life expectancy and morbidity related to both the tumour, and the patient's age, the ability to tolerate treatment and the effect this will have on their subsequent function and quality of life.

Consequent to all the above challenges, the elderly breast cancer patient may not receive the optimal treatment, resulting in poorercancer-specific survival and overall survival outcomes [12] [16].

The purpose of this study is to examine the differences in characteristics of breast tumors and the implemented treatments across different age groups in our multi-ethnic Asian population, and how these differences impact on breast cancer specific and all-cause mortality of invasive breast cancer (IBC).

\section{Material and Methods}

\subsection{Study Design and Sample Selection}

The study is a retrospective review of prospectively entered data on patients' 
tumour characteristics, treatment regimen and outcomes of interest from the breast cancer database at Changi General Hospital, a tertiary hospital in Singapore. This database includes all patients diagnosed and/or treated at this institution. All patients with invasive breast cancer (IBC) diagnosed and treated between 1 January 1991 and 31 December 2008 were included. There was no sample size calculation performed. Patients were followed up until 30 June 2013 with a minimum of follow-up period of 5 years. Patients who had initially sought definitive surgical treatment at another institution and patients who defaulted before definitive treatment were excluded from this study. Patients aged younger than 40 years were excluded as well. Surgical options were discussed in detail with each patient, before the decision on the type of surgery to be undertaken was made. All adjuvant therapy was recommended after a multi-disciplinary discussion. However, some patients either refused therapy or were non-compliant with it.

\subsection{Data Extraction and Measurement}

The following information for IBC patients was extracted: Demographic and clinical data (age, race, co-morbidities, presenting complaint, side, site, clinically palpable axillary nodes, bilaterality, tumour stage, Nottingham Prognostic Index (NPI) score, presence of and site of metastasis), pathological data (histology, grade, estrogen receptor (ER) status, progesterone receptor (PR) status, HER2 status, presence of vascular invasion, micro-calcification), treatment data (type of breast surgery, axillary and reconstructive surgery; adjuvant therapy including chemotherapy, hormonal or radiation therapy) and outcome data (breast cancer mortality and all-cause mortality). ER, PR and HER2 receptor staining was performed on paraffin sections of formalin-fixed tissue using Dako 1D5 Anti-mouse antibody at 1:50 dilution, Dako PgR636 Anti-mouse antibody at 1:200 dilution, and Thermo Scientific clone SP3 anti-rabbit antibody RM-9013-S1 at 1:200 dilution respectively. ER and PR receptor status was considered positive if $\geq 1 \%$ of the cells displayed a minimal of $1+$ nuclear-staining intensity. HER2 status were considered positive if cerb B2 stains showed uniform intense membranous staining of $>30 \%$ of the tumour cells. In cases that the cerbB2 stains were equivocal, fluorescence in situ hybridisation (FISH) tests were done to establish the HER2 status using the PathVysion kit (Abbott Molecular).

The patients were categorised into three groups according to age at presentation: Young (40 - 64 years), young elderly (65 - 74 years) and old elderly (75 years and above).

Outcomes were defined as time-to-event data types, where events were categorized as all-cause mortality, breast cancer mortality, or last visit alive. The reference time was the date of first treatment. Local and distant recurrence rates were also considered.

\subsection{Statistical Analysis}

Demographics, clinical, pathological, treatment and survival outcome charac- 
teristics were summarized as mean (standard deviation (SD)), median (Inter-quartile range (IQR)) for continuous variable and frequency with corresponding proportion for categorical variables. Association between age groups and categorical variables was evaluated using Fisher's exact test. Kaplan-Meier (KM) curve was used to depict survival rates by age groups and Log rank (or Wilcoxon) test was used to evaluate the association between the age groups and time-to-event outcomes like overall survival, breast cancer mortality and all-cause mortality. Univariateand multivariate Cox Proportional Hazard ( $\mathrm{PH})$ regression models were used to identify risk factors associated with breast cancer related mortality and all-cause mortality.

Significance level was set at 5\% and all tests were two sided.SAS version 9.3 software (SAS Institute, Cary, North Carolina) was used for the analyses. For survival analysis PROC PHREG procedure was used.

This study was reviewed and approved by an independent ethics review board at Changi General Hospital, Singapore.

\section{Results}

\subsection{Patient and Tumour Characteristics}

In total, 893 invasive breast cancers was diagnosed in 879 patients, with a median age of 55 years (min: 40 years, max: 91 years) were seen. Median follow-up was 5.9 years (range: 0.0 years to 21.0 years).There were 103 (11.53\%), 147 $(16.5 \%)$ and $643(72.0 \%)$ old elderly, young elderly and young patients respectively, with the racial distribution being similar to our national demographics [17].

A palpable lump (86.9\%) was the most common presentation, while cardiovascular diseases $(28.4 \%)$ and diabetes mellitus (14.0\%) were the most common co-morbidities across all age groups. Although the patients over 65 years of age had significantly more co-morbidities than the young patients $(66.7 \%$ vs. $33.3 \%$ with $\mathrm{P}=0.0003)$, there were no significant differences in co-morbidities between the young elderly and the old elderly groups (33.3\% vs. $66.7 \%$ with $\mathrm{P}=0.1298)$. Significantly more old elderly patients $(22.2 \%)$ presented with metastatic disease, compared to the young elderly $(9.7 \%)$ and young $(6.7 \%)$ patients $(\mathrm{P}<0.001)$. The sites of metastases were similar among the 3 groups (Table 1).

The majority $(86.9 \%)$ of breast cancers were ductal carcinomas. There was no difference in ER, PR or HER2 positivity among the age groups. However, there were fewer Grade 1 tumours in the young patient group (12.1\%) compared to the young elderly $(19.3 \%)$ and old elderly $(19.6 \%)$ patients $(\mathrm{P}=0.047)$. Old elderly patients had significantly more stage 4 cancers compared to the other two groups $(\mathrm{P}<0.001)$ (Table 2$)$.

\subsection{Treatments Received}

Breast conservation was more common than mastectomy among young patients with early stage (stage $1-2$ ) breast cancer compared to the 2 elderly groups. The 
Table 1. Demographic and clinical characteristics of invasive breast cancer (IBC) according to age groups.

\begin{tabular}{|c|c|c|c|c|}
\hline & \multicolumn{4}{|c|}{ Age Group (in Years) } \\
\hline & $\begin{array}{c}40-64(\%) \\
{[N=643]}\end{array}$ & $\begin{array}{c}65-74(\%) \\
{[N=147]}\end{array}$ & $\begin{array}{l}\geq 75(\%) \\
{[N=103]}\end{array}$ & $\mathrm{p}$ value \\
\hline \multicolumn{5}{|c|}{ Race } \\
\hline Chinese & $468(72.8)$ & $103(70.1)$ & $81(78.6)$ & \multirow{4}{*}{0.572} \\
\hline Malay & $114(17.7)$ & $29(19.7)$ & $11(10.7)$ & \\
\hline Indian & $33(5.1)$ & $8(5.4)$ & $7(6.8)$ & \\
\hline Others & $28(4.4)$ & $7(4.8)$ & $4(3.9)$ & \\
\hline \multicolumn{5}{|c|}{ Co-morbidities } \\
\hline Diabetes MELLITUS & $60(9.3)$ & $38(25.9)$ & $27(26.2)$ & $<0.001$ \\
\hline Cardiovascular disease & $124(19.3)$ & $76(51.7)$ & $54(52.4)$ & $<0.001$ \\
\hline Other disease & $38(5.9)$ & $16(10.9)$ & $19(18.5)$ & $<0.001$ \\
\hline Pulmonary disease & $29(4.5)$ & $4(2.7)$ & $3(2.9)$ & \\
\hline Central nervous system disease & $4(0.6)$ & $11(7.5)$ & $14(13.6)$ & \\
\hline Renal disease & $4(0.6)$ & $1(0.7)$ & $1(1.0)$ & \\
\hline Liver disease & $4(0.6)$ & $0(0.0)$ & $2(1.9)$ & \\
\hline \multicolumn{5}{|c|}{ Clinical characteristics } \\
\hline \multicolumn{5}{|c|}{ Complaint } \\
\hline Presence of lump & $555(86.3)$ & $127(87.0)$ & $94(92.2)$ & \multirow{3}{*}{0.143} \\
\hline $\begin{array}{l}\text { Screening detected } \\
\text { (U/S or } M M G)\end{array}$ & $60(9.3)$ & $8(5.5)$ & $5(4.9)$ & \\
\hline Others (Pain/nipple discharge) & $28(4.4)$ & $11(7.5)$ & $3(2.9)$ & \\
\hline Bilateral CANCER & $39(6.1)$ & $15(10.2)$ & $8(7.8)$ & 0.176 \\
\hline Palpable axillary LN & $82(17.3)$ & $22(19.8)$ & $19(24.7)$ & 0.283 \\
\hline Presence of metastasis & $42(6.7)$ & $13(9.7)$ & $21(22.2)$ & $<0.001$ \\
\hline \multicolumn{5}{|l|}{ Metastatic site } \\
\hline Bone & $16(38.1)$ & $4(30.8)$ & $8(38.1)$ & \multirow{5}{*}{0.823} \\
\hline Lung/pleural & $4(9.5)$ & $3(23.1)$ & $2(9.5)$ & \\
\hline Liver (single) & $2(4.8)$ & $0(0.0)$ & $1(4.8)$ & \\
\hline Distant LN/brain & $2(4.8)$ & $2(15.4)$ & $2(9.5)$ & \\
\hline Multiple sites & $18(42.9)$ & $4(30.8)$ & $8(38.1)$ & \\
\hline
\end{tabular}

Abbreviations: U/S, ultrasound; MMG, mammogram; LN, lymph node.

young patients (Table 3) almost exclusively undertook breast reconstruction. Across all stages, the uptake of adjuvant therapy decreased as the age increased. In Stage 1, this lower uptake of adjuvant therapy did not reach statistical significance. However, in Stage 2 and Stage 3 cancers, the majority of young women received adjuvant therapy, while much fewer in the young elderly and old elderly groups underwent chemotherapy and radiotherapy. The exception was 
Table 2. Pathological characteristics according to age groups.

\begin{tabular}{|c|c|c|c|c|}
\hline & \multicolumn{3}{|c|}{ Age group (in Years) } & \multirow[b]{2}{*}{$\mathrm{p}$ value } \\
\hline & $40-64(\%)$ & $65-74(\%)$ & $\geq 75(\%)$ & \\
\hline \multicolumn{5}{|l|}{ Histological type } \\
\hline Ductal & $564(90.4)$ & $127(88.2)$ & $85(85.0)$ & \multirow{4}{*}{0.002} \\
\hline Lobular & $34(5.5)$ & $5(3.5)$ & $3(3.0)$ & \\
\hline Mucinous/mucoid & $16(2.6)$ & $9(6.3)$ & $12(12.0)$ & \\
\hline Others & $10(1.6)$ & $3(2.1)$ & $0(0.0)$ & \\
\hline \multicolumn{5}{|l|}{ Grade } \\
\hline 1 & $75(12.1)$ & $27(19.3)$ & $19(19.6)$ & \multirow{3}{*}{0.047} \\
\hline 2 & $232(37.4)$ & $56(40.0)$ & $36(37.1)$ & \\
\hline 3 & $314(50.6)$ & $57(40.7)$ & $42(43.3)$ & \\
\hline ER status & $388(66.7)$ & $97(74.1)$ & $65(69.9)$ & 0.252 \\
\hline PR status & $309(55.0)$ & $72(55.4)$ & $51(54.8)$ & 1.000 \\
\hline \multicolumn{5}{|l|}{ HER2 } \\
\hline Positive & $152(34.9)$ & $38(36.9)$ & $23(30.3)$ & \multirow[t]{3}{*}{0.515} \\
\hline Negative & $247(56.7)$ & $59(57.3)$ & $43(56.6)$ & \\
\hline Equivocal & $37(8.5)$ & $6(5.8)$ & $10(13.2)$ & \\
\hline Vascular invasion & $228(36.3)$ & $54(38.0)$ & $28(31.5)$ & 0.585 \\
\hline Micro-calcification & $198(58.1)$ & $47(56.6)$ & $30(51.7)$ & 0.650 \\
\hline \multicolumn{5}{|l|}{ Breast cancer staging } \\
\hline Stage 1 & $179(27.8)$ & $31(21.1)$ & $19(18.5)$ & \multirow{4}{*}{$<0.001$} \\
\hline Stage 2 & $298(46.4)$ & $75(51.0)$ & $40(38.8)$ & \\
\hline Stage 3 & $124(19.3)$ & $27(18.4)$ & $19(18.5)$ & \\
\hline Stage 4 & $42(6.5)$ & $14(9.5)$ & $25(24.3)$ & \\
\hline \multicolumn{5}{|c|}{ Nottingham prognostic index } \\
\hline Good & $147(24.9)$ & $33(26.2)$ & $28(35.4)$ & \\
\hline Moderate & $276(46.8)$ & $64(50.8)$ & $26(32.9)$ & 0.082 \\
\hline Poor & $167(28.3)$ & $29(23.0)$ & $25(31.7)$ & \\
\hline
\end{tabular}

Abbreviations: ER, estrogen receptor; PR, progesterone receptor; HER2, human epidermal growth factor receptor.

adjuvant hormonal therapy, which showed similar rates among all the age groups (Table 3).

\subsection{Recurrence and Survival Outcomes}

Local and distant recurrence rates were comparable during the study period across all groups. There were no statistical significant differences in terms of recurrence between different stages and sites of recurrence as well (Table 4). Overall median survival time for old elderly, young elderly and young patients 
Table 3. Treatment received according to age groups.

\begin{tabular}{|c|c|c|c|c|}
\hline & \multicolumn{3}{|c|}{ Age group (in Years) } & \multirow[b]{2}{*}{$\mathrm{p}$ value } \\
\hline & $40-64(\%)$ & $65-74(\%)$ & $\geq 75(\%)$ & \\
\hline \multicolumn{5}{|l|}{ Surgery } \\
\hline Stage $1(\mathrm{n})$ & 179 & 31 & 19 & \\
\hline Mastectomy & $115(64.2)$ & $27(87.1)$ & $17(89.5)$ & \\
\hline Conservation & $63(35.2)$ & $4(12.9)$ & $2(10.5)$ & 0.013 \\
\hline None & $1(0.6)$ & $0(0.0)$ & $0(0.0)$ & \\
\hline Stage $2(\mathrm{n})$ & 298 & 75 & 40 & \\
\hline Mastectomy & $242(81.2)$ & $70(93.3)$ & $35(87.5)$ & \\
\hline Conservation & $55(18.5)$ & $4(5.3)$ & $4(10.0)$ & 0.007 \\
\hline None & $1(0.3)$ & $1(1.3)$ & $1(2.5)$ & \\
\hline Stage $3(\mathrm{n})$ & 124 & 27 & 19 & \\
\hline Mastectomy & $113(91.1)$ & $25(92.6)$ & $16(84.2)$ & \\
\hline Conservation & $10(8.1)$ & $0(0.0)$ & $1(5.3)$ & 0.029 \\
\hline None & $1(0.8)$ & $2(7.4)$ & $2(10.5)$ & \\
\hline Stage 4\# (n) & 41 & 14 & 24 & 1 \\
\hline Mastectomy & $26(63.4)$ & $10(71.4)$ & $8(33.3)$ & \\
\hline Conservation & $2(4.9)$ & $1(7.1)$ & $1(4.2)$ & 0.050 \\
\hline None & $13(31.7)$ & $3(21.4)$ & $15(62.5)$ & \\
\hline Breast reconstruction^ ${ }^{\wedge}$ & $40(6.3)$ & $1(0.7)$ & $0(0.0)$ & $<0.001$ \\
\hline \multicolumn{5}{|c|}{ Adjuvant Therapy* } \\
\hline \multicolumn{5}{|c|}{ Stage 1} \\
\hline Adjuvant & $135(77.1)$ & $19(65.5)$ & $10(55.6)$ & 0.079 \\
\hline Chemotherapy & $49(28.8)$ & $1(3.4)$ & $0(0.0)$ & $<0.001$ \\
\hline Radiotherapy & $62(36.5)$ & $4(13.8)$ & $1(5.6)$ & 0.002 \\
\hline Hormone & 95 (55.6) & $18(62.1)$ & $10(55.6)$ & 0.804 \\
\hline \multicolumn{5}{|c|}{ Stage 2} \\
\hline Adjuvant & $262(91.3)$ & $61(87.1)$ & $22(59.5)$ & $<0.001$ \\
\hline Chemotherapy & $197(68.6)$ & $15(21.7)$ & $1(2.7)$ & $<0.001$ \\
\hline Radiotherapy & $100(35.3)$ & $11(15.9)$ & $5(13.5)$ & $<0.001$ \\
\hline Hormone & $174(61.5)$ & $55(78.6)$ & $23(62.2)$ & 0.024 \\
\hline \multicolumn{5}{|l|}{ Stage 3} \\
\hline Adjuvant & $102(90.3)$ & $25(96.2)$ & $10(66.7)$ & 0.015 \\
\hline Chemotherapy & $98(86.7)$ & $14(60.9)$ & $1(6.7)$ & $<0.001$ \\
\hline Radiotherapy & $94(83.9)$ & $19(79.2)$ & $2(13.3)$ & $<0.001$ \\
\hline Hormone & $65(59.1)$ & $18(75.0)$ & $9(60.0)$ & 0.377 \\
\hline \multicolumn{5}{|l|}{ Stage 4\# } \\
\hline \multicolumn{5}{|l|}{ Palliative } \\
\hline Chemotherapy & $17(50.0)$ & $0(0.0)$ & $0(0.0)$ & $<0.001$ \\
\hline Radiotherapy & $12(37.5)$ & $2(15.4)$ & $5(21.7)$ & 0.292 \\
\hline Hormone & $22(64.7)$ & $7(53.8)$ & $16(69.6)$ & 0.643 \\
\hline
\end{tabular}

$\wedge$ The percentages are calculated based on the total number of patients in each age group. ${ }^{*}$ The percentages are calculated based on the "n" number of patients in each stage, as stated in the surgery section. \#Treatment in this group was for local control and palliation. Abbreviations: $n$, number. 
Table 4. Local and distant recurrence rates according to age groups (stages 1 - 3).

\begin{tabular}{|c|c|c|c|c|}
\hline & \multicolumn{3}{|c|}{ Age group (in Years) } & \multirow[b]{2}{*}{$\mathrm{p}$ value } \\
\hline & $40-64(\%)$ & $65-74(\%)$ & $\geq 75(\%)$ & \\
\hline Local recurrence & $49(8.6)$ & $13(10.5)$ & $6(8.3)$ & 0.768 \\
\hline \multicolumn{5}{|c|}{ Local recurrence by stage } \\
\hline Stage 1 & $12(25.5)$ & $2(15.4)$ & $1(16.7)$ & \\
\hline Stage 2 & $26(51.1)$ & $10(76.9)$ & $2(33.3)$ & 0.248 \\
\hline Stage 3 & $11(23.4)$ & $1(7.7)$ & $3(50.0)$ & \\
\hline Distant recurrence & $89(14.8)$ & $24(18.3)$ & $12(13.6)$ & 0.527 \\
\hline Bone & $17(19.3)$ & $1(4.2)$ & $1(8.3)$ & \\
\hline Lung/pleural & $12(13.6)$ & $2(8.3)$ & $3(25.0)$ & \\
\hline Liver & $5(5.7)$ & $0(0.0)$ & $0(0.0)$ & \\
\hline Brain & $4(4.6)$ & $0(0.0)$ & $1(8.3)$ & \\
\hline Nodes & $13(14.8)$ & $2(8.3)$ & $4(33.3)$ & \\
\hline Multiple sites & $37(42.1)$ & $19(79.2)$ & $3(25.0)$ & \\
\hline \multicolumn{5}{|c|}{ Distant recurrence by stage } \\
\hline Stage 1 & $10(12.1)$ & $3(13.0)$ & $0(0.0)$ & \\
\hline Stage 2 & $45(53.0)$ & $14(60.9)$ & $3(33.3)$ & 0.358 \\
\hline Stage 3 & $29(34.9)$ & $6(26.1)$ & $6(66.7)$ & \\
\hline
\end{tabular}

were 4.2 (95\% CI: 3.0 - 5.5), 8.7 (95\% CI: 7.7 - 12.6) and 13.0 (95\% CI: 12.1 - not estimable) years respectively. Overall survival at 5 years were $46.4 \%$ (95\% CI: $35.6 \%-56.4 \%$ ), $78.6 \%$ (95\% CI: $70.4 \%-84.8 \%$ ) and $83.4 \%$ (95\% CI: $80.0 \%-$ $86.3 \%$ ) and breast cancer specific 5-year survival rates were $64.7 \%$ (95\% CI: $53.4 \%-73.8 \%$ ), $82.4 \%$ (95\% CI: $74.4 \%-88.0 \%$ ) and $84.9 \%$ (95\% CI: $81.6 \%-$ 87.7\%) for old elderly, young elderly and young patients respectively.

A total of 187 breast cancer deaths and 69 non-breast cancer deaths occurred during the study period. Both breast cancer mortality and all-cause mortality increased significantly as age increased $(\mathrm{P}<0.001, \mathrm{P}<0.001)$. In both the young elderly and old elderly groups, there were more deaths resulting from breast cancer than from other causes (Table 5). Figure 1 and Figure 2 show the Kaplan Meier survival curves for breast cancer and all-cause mortality for all age groups respectively.

Univariate Cox $\mathrm{PH}$ regression analysis showed that the following risk factors significantly influenced both breast cancer survival and overall survival: increasing age (groups), having clinically palpable axillary lymph nodes, a high tumour grade, negative ER and PR status, evidence of vascular invasion, advanced tumour stage, presence of metastasis, a poor NPI score, undergoing a mastectomy, and having no chemotherapy. Multivariate analysis of Cox PH regression showed that only clinically palpable axillary nodes, an advanced stage, presence of metastasis, negative PR receptor status, a poor NPI score and having no 
Table 5. Mortality characteristics of according to age groups.

\begin{tabular}{ccccc}
\hline & \multicolumn{3}{c}{ Age group (in Years) } & \multirow{2}{*}{ p value } \\
\cline { 2 - 4 } & $40-64(\%)$ & $\mathbf{6 5 - 7 4 ( \% )}$ & $>75(\%)$ & \\
\hline Death from breast cancer & $117(19.6)$ & $35(25.0)$ & $35(35.0)$ & $<0.001 \dagger$ \\
& & & & $<0.001^{*}$ \\
Death from other causes & $23(3.9)$ & $20(14.3)$ & $26(26.0)$ & $<0.001 \dagger$ \\
& & & & $<0.001^{*}$ \\
All-cause mortality & $140(23.5)$ & $55(39.3)$ & $61(61.0)$ & $<0.001 \dagger$ \\
& & & & $<0.001^{*}$ \\
\hline
\end{tabular}

Note: ${ }^{*} \mathrm{p}$ value based on Log Rank test. $\uparrow-p$-value based on Wilcoxon test.

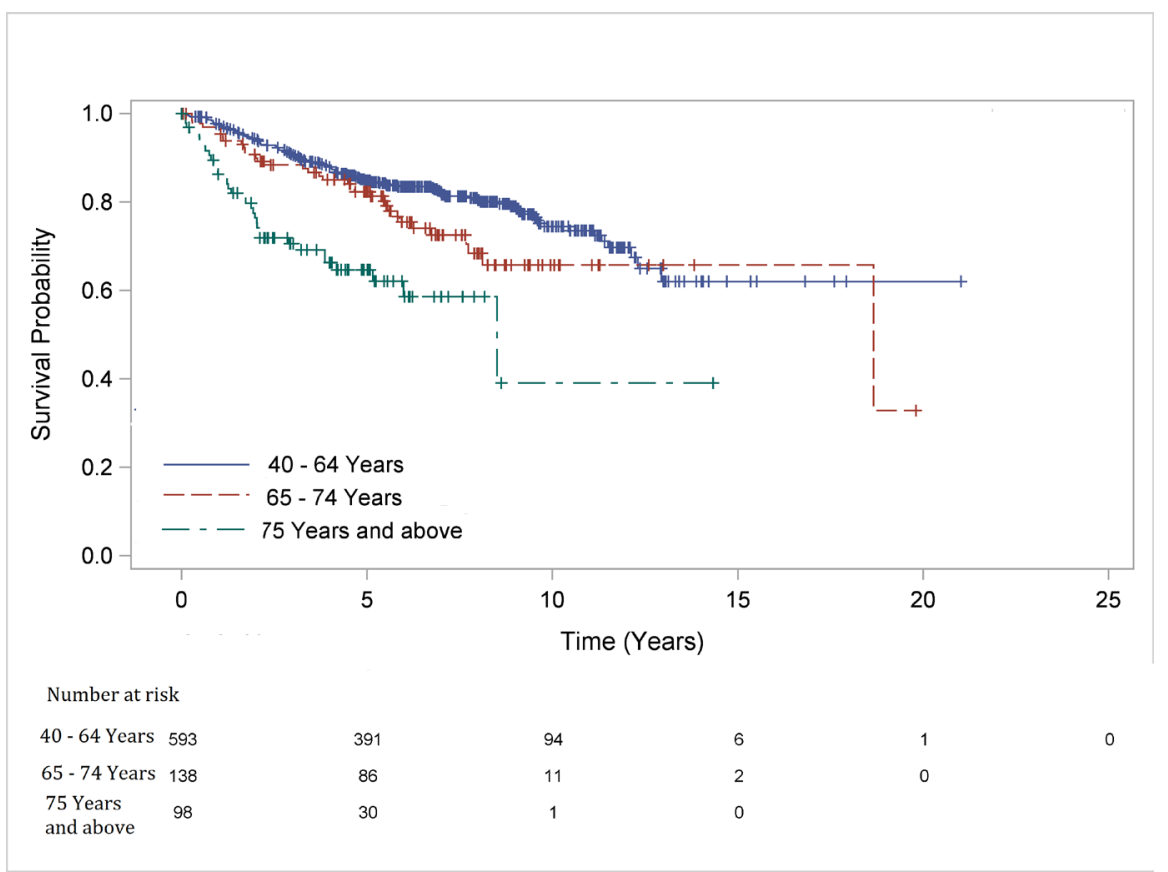

Figure 1. Proportion of survival from breast cancer mortality by age groups.

chemotherapy were independent predictors of decreased overall survival and breast cancer related survival. Age was not an independent predictor of overall or breast cancer specific survival on multivariate Cox $\mathrm{PH}$ regression analysis (Table 6).

\section{Discussion}

To our knowledge, this is the first paper comparing older breast cancer patients ( $\geq 65$ years) with younger patients ( $40-64$ years) in an Asian setting. We did not include patients below 40 years of age, as these very young patients are known to have more aggressive tumours with a higher predisposition for genetic influences [15] [18].

Our results show that the old elderly patient group had tumours that exhibited more favourable tumour characteristics. There were a higher proportion of non-ductal carcinomas (lobular and mucinous/mucinoid), which are known to 


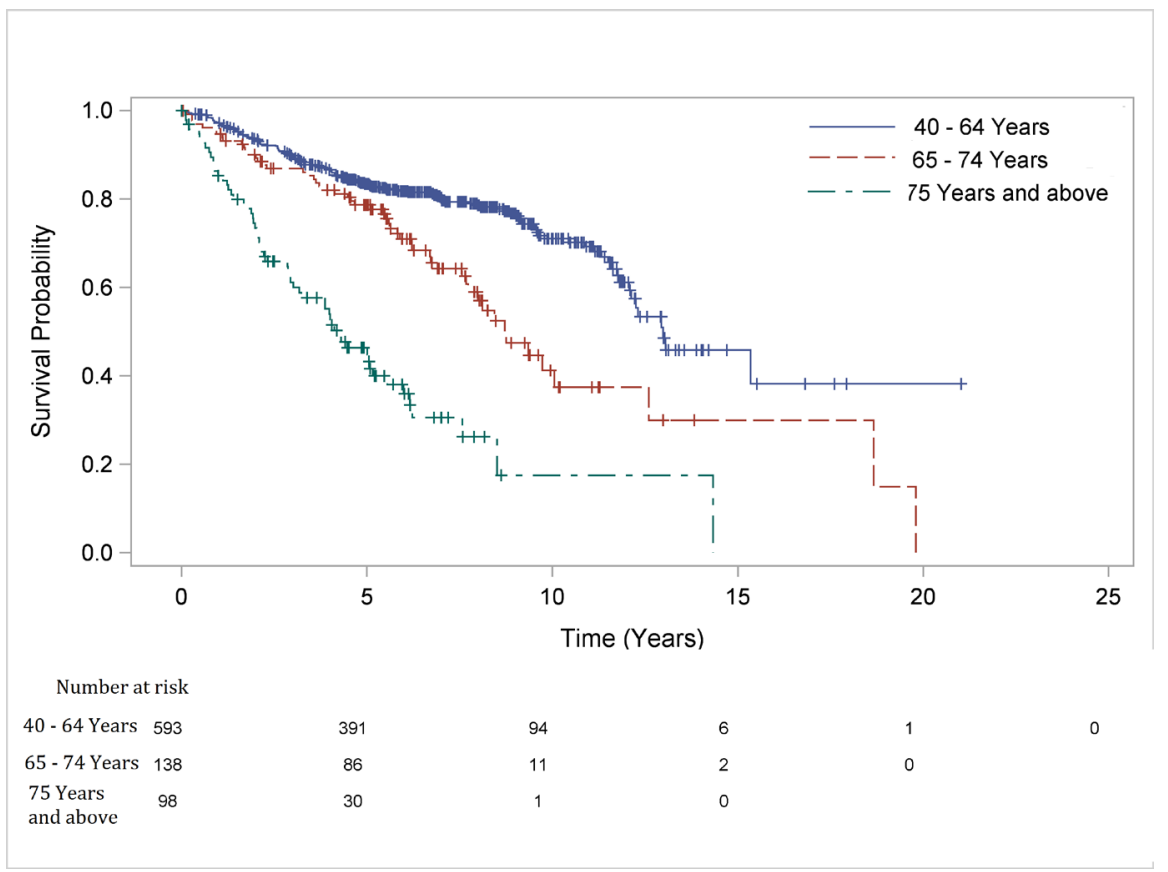

Figure 2. Proportion of survival from all-cause mortality by age groups.

Table 6. Multivariate analysis on various risk factors for invasive breast cancer.

\begin{tabular}{ccccc}
\hline \multirow{2}{*}{ Variables } & \multicolumn{2}{c}{ Overall survival } & \multicolumn{2}{c}{ Breast cancer related survival } \\
\cline { 2 - 5 } & Hazard ratio (CI) & p-value & Hazard ratio (CI) & p-value \\
\hline PR status (Ref: Yes) & $2.0(1.3-2.9)$ & 0.0006 & $3.6(2.3-5.6)$ & $<0.0001$ \\
Stage (Ref: Stage 1) & & $<0.0001 \dagger$ & & $<0.0001 \dagger$ \\
Stage 2 & $3.1(1.6-6.1)$ & 0.0009 & $2.1(0.9-4.5)$ & 0.0728 \\
Stage 3 & $4.1(1.9-9.2)$ & 0.0005 & $2.6(1-6.7)$ & 0.0434 \\
Stage 4 & $12.7(5.4-29.8)$ & $<0.0001$ & $12.8(4.9-33.5)$ & $<0.0001$ \\
Chemotherapy (Ref: No) & $0.3(0.2-0.4)$ & $<0.0001$ & $0.4(0.3-0.6)$ & $<0.0001$ \\
Hormonal therapy (Ref: No) & $0.7(0.5-1)$ & 0.0419 & & $0.0002 \dagger$ \\
Nottingham prognostic & & $0.0002 \dagger$ & & 0.0018 \\
index (Ref: Poor) & & 0.0009 & $0.2(0.1-0.6)$ & 0.0002 \\
Good & $0.3(0.1-0.6)$ & 0.0001 & $0.4(0.2-0.6)$ & \\
Moderate & $0.4(0.3-0.7)$ & & & \\
\hline
\end{tabular}

Note: $\uparrow$ type 3 p-value. Abbreviation: PR, progesterone receptor; Ref, reference group.

have better biological phenotypes compared to ductal carcinomas [19] [20]. The young elderly and old elderly patients in our study were also noted to have more Grade 1 and fewer Grade 3 tumours than the young patients. This is similar to the findings of Diab et al. [21], who analysed patients from the San Antonio and SEER databases, and found that their older patients had more lobular and mucinous tumours, as well as more favourable tumour biologic characteristics such as diploidy, lower S-phase fraction and normal p 53. However, unlike 
Diab's study, we did not find any difference in the hormonal receptor status or HER2 receptor status positivity among the different age groups. Naito et al. [22] compared Japanese patients who were $>75$ years old with those between 60 to 74 years old in which they did not find any differences in hormone receptor status. This could suggest that breast cancer tumour characteristics in this particular subgroup of Asian older patients may be different from that of the Western populations.

As noted by Gennari et al. [4], older patients present later than their younger counterparts do, with more having clinically palpable axillary lymph nodes, and a higher stage at presentation. Possible reasons may be a decreased awareness of breast cancer in the elderly, a reluctance to seek treatment, lesser access to medical care and financial concerns.

Both the young elderly and old elderly patients with early breast cancer in our study were more likely to undergo mastectomy compared to the young patients. This may reflect both the patients' and surgeons' greater emphasis on effective treatment without radiation, and a lesser priority towards cosmesis forelderly Asian patients. Factors such as decreased mobility and difficulty in travelling for daily radiation therapy may be factors for consideration when choosing the type of surgery [23].

In our study, young elderly and old elderly patients underwent chemotherapy and radiotherapy less often, and this was most obvious in the old elderly group. Many other studies, including a study from MD Anderson have also shown that older patients were less likely to undergo recommended treatment for breast cancer [12] [24] [25]. Hormonal therapy rates, however, were similar across all the age groups, and this was noted by Diab et al. [21] as well. A recent paper from Singapore showed that up to $72.0 \%$ of cancer physicians were less likely to treat a fit but older patient aggressively [26].

Undertreatment of elderly breast cancers have been noted in several studies, but its impact on survival outcomes are still uncertain. In the studies by Rocco et al. [27] and Gajdos et al. [28], undertreatment of elderly breast cancers did not result in worse recurrence free survival. However, other studies have shown that undertreatment of breast cancers in elderly patients significantly decreases survival [29] [30]. We found breast cancer specific mortality to increase with increasing age despite the more favourable characteristics of tumours in the elderly patients. However, on multivariate analysis, age was not an independent predictor of breast cancer specific survival. This suggests that the delay in diagnosis and treatment of breast cancer in both our young elderly and old elderly patient groups could have resulted in poorer survival. The updated recommendations of the International Society of Geriatric Oncology (SIOG) and European Society of Breast Cancer Specialists (EUSOMA) are not to base management decisions on age alone, but to include geriatric assessment, competing causes of mortality, drug safety and compliance, patient preferences, and barriers to treatment as factors to take into consideration [8]. Female life expectancy in Singapore is 85.1 years, comparable to that many European countries, including Switzerland, 
United Kingdom, and United States [31]. Hence, the results of this paper may also have relevance to Western populations.

We acknowledge that there are some limitations in our paper. Firstly, this is a retrospective analysis conducted on prospectively collected data. There was some missing data, but this was unlikely to skew the statistics in view of the large sample population. As the study period spanned more than a decade, therapies had evolved over this time, thus giving rise to different treatment options offered and administered to patients presenting at different times during the study period. This could potentially influence the treatment outcomes. Treatment options offered were also up to the discretion of the attending physician. Further, we did not have data on compliance to treatment. Adherence of the patients to hormonal therapy has been shown to be lower in the old elderly age group [32]. We also did not collect data on functional status, cognition, socioeconomic status and the severity of comorbidities, which may be potential confounders. Further studies which incorporate assessments of the above (comprising a comprehensive geriatric assessment) would be useful in determining the role these factors play in influencing survival outcomes [33] [34] [35]. This may then help us determine which elderly patients would benefit most from adherence to standard treatment guidelines.

\section{Conclusion}

Our results indicate that elderly patients had more favorable tumor characteristics. However, there was a tendency towards undertreatment of breast cancer in the elderly patients and this could have contributed to the poorer survival outcomes. Hence, breast cancer treatment of elderly patients should not be based on chronological age alone; but must be individualized to the patient taking into consideration their function, comorbidities, quality of life and expected life expectancy, and weighing the perceived benefits and risks of treatment.

\section{Acknowledgements}

The authors would like to thank Dr. Kristján Skúli Ásgeirsson, Nottingham Breast Institute, for his invaluable help in the preparation of this manuscript.

\section{Conflicts of Interest/Funding}

The authors declare no conflicts of interest, and no funding was received.

\section{References}

[1] National Registry of Diseases Office S. (2012) Trends of Female Breast Cancer in Singapore 2006-2010.

[2] Bray, F., Jemal, A., Grey, N., Ferlay, J. and Forman, D. (2012) Global Cancer Transitions According to the Human Development Index (2008-2030): A Population-Based Study. The Lancet Oncology, 13, 790-801.

https://doi.org/10.1016/S1470-2045(12)70211-5

[3] Institute. NC. SEER Cancer Statistics Review, 1975-2011. 
[4] Gennari, R., Curigliano, G., Rotmensz, N., Robertson, C., Colleoni, M., Zurrida, S., et al. (2004) Breast Carcinoma in Elderly Women: Features of Disease Presentation, Choice of Local and Systemic Treatments Compared with Younger Postmenopasual Patients. Cancer, 101, 1302-1310. https://doi.org/10.1002/cncr.20535

[5] United Nations DoEaSA, Population Division (2013) World Population Prospects: The 2012 Revision, Volume II, Demographic Profiles.

[6] Luque, M., Arranz, F., Cueva, J.F., de Juan, A., Garcia-Teijido, P., Calvo, L., et al. (2014) Breast Cancer Management in the Elderly. Clinical \& translational Oncology: Official Publication of the Federation of Spanish Oncology Societies and of the National Cancer Institute of Mexico, 16, 351-361. https://doi.org/10.1007/s12094-013-1113-2

[7] Wildiers, H., Heeren, P., Puts, M., Topinkova, E., Janssen-Heijnen, M.L., Extermann, M., et al. (2014) International Society of Geriatric Oncology Consensus on Geriatric Assessment in Older Patients with Cancer. Journal of Clinical Oncology: Official Journal of the American Society of Clinical Oncology, [Research Support, Non-U.S. Gov't Review], 32, 2595-2603.

[8] Biganzoli, L., Wildiers, H., Oakman, C., Marotti, L., Loibl, S., Kunkler, I., et al. (2012) Management of Elderly Patients with Breast Cancer: Updated Recommendations of the International Society of Geriatric Oncology (SIOG) and European Society of Breast Cancer Specialists (EUSOMA). The Lancet Oncology, 13, e148-e60. https://doi.org/10.1016/S1470-2045(11)70383-7

[9] Anderson, W.F., Katki, H.A. and Rosenberg, P.S. (2011) Incidence of Breast Cancer in the United States: Current and Future Trends. Journal of the National Cancer Institute, 103, 1397-1402. https://doi.org/10.1093/jnci/djr257

[10] de Munck, L., Schaapveld, M., Siesling, S., Wesseling, J., Voogd, A.C., Tjan-Heijnen, V.C., et al. (2011) Implementation of Trastuzumab in Conjunction with Adjuvant Chemotherapy in the Treatment of Non-Metastatic Breast Cancer in the Netherlands. Breast Cancer Research and Treatment, 129, 229-233. https://doi.org/10.1007/s10549-011-1451-0

[11] Wildiers, H., Kunkler, I., Biganzoli, L., Fracheboud, J., Vlastos, G., Bernard-Marty, C., et al. (2007) Management of Breast Cancer in Elderly Individuals: Recommendations of the International Society of Geriatric Oncology. The Lancet Oncology, 8 , 1101-1115. https://doi.org/10.1016/S1470-2045(07)70378-9

[12] Schonberg, M.A., Marcantonio, E.R., Li, D., Silliman, R.A., Ngo, L. and McCarthy, E.P. (2010) Breast Cancer among the Oldest Old: Tumor Characteristics, Treatment Choices, and Survival. Journal of Clinical Oncology: Official Journal of the American Society of Clinical Oncology, 28, 2038-2045. https://doi.org/10.1200/JCO.2009.25.9796

[13] Javid, S.H., Unger, J.M., Gralow, J.R., Moinpour, C.M., Wozniak, A.J., Goodwin, J.W., et al. (2012) A Prospective Analysis of the Influence of Older Age on Physician and Patient Decision-Making When Considering Enrollment in Breast Cancer Clinical Trials (SWOG S0316). The Oncologist, 17, 1180-1190.

https://doi.org/10.1634/theoncologist.2011-0384

[14] Denson, A.C. and Mahipal, A. (2014) Participation of the Elderly Population in Clinical Trials: Barriers and Solutions. Cancer Control: Journal of the Moffitt Cancer Center, 21, 209-214.

[15] Lee, H.B. and Han, W. (2014) Unique Features of Young Age Breast Cancer and Its Management. Journal of Breast Cancer, 17, 301-307.

https://doi.org/10.4048/jbc.2014.17.4.301 
[16] Rosso, S., Gondos, A., Zanetti, R., Bray, F., Zakelj, M., Zagar, T., et al. (2010) Up-to-Date Estimates of Breast Cancer Survival for the Years 2000-2004 in $11 \mathrm{Eu}$ ropean Countries: The Role of Screening and a Comparison with Data from the United States. European Journal of Cancer, 46, 3351-3357. https://doi.org/10.1016/j.ejca.2010.09.019

[17] Department of Statistics (2014) S. Monthly Digest.

[18] Walker, R.A., Lees, E., Webb, M.B. and Dearing, S.J. (1996) Breast Carcinomas Occurring in Young Women (<35 Years) Are Different. British Journal of Cancer, 74, 1796-800. https://doi.org/10.1038/bjc.1996.632

[19] Di Saverio, S., Gutierrez, J. and Avisar, E. (2008) A Retrospective Review with Long Term Follow up of 11,400 Cases of Pure Mucinous Breast Carcinoma. Breast Cancer Research and Treatment, 111, 541-547. https://doi.org/10.1007/s10549-007-9809-Z

[20] Arpino, G., Bardou, V.J., Clark, G.M. and Elledge, R.M. (2004) Infiltrating Lobular Carcinoma of the Breast: Tumor Characteristics and Clinical Outcome. Breast Cancer Research: BCR, 6, R149-R156. https://doi.org/10.1186/bcr767

[21] Diab, S.G., Elledge, R.M. and Clark, G.M. (2000) Tumor Characteristics and Clinical Outcome of Elderly Women with Breast Cancer. Journal of the National Cancer Institute, 92, 550-556. https://doi.org/10.1093/jnci/92.7.550

[22] Naito, Y., Mukai, H. and Nagai, S. (2010) Elderly Breast Cancer Therapy: A Japanese Experience. Japanese Journal of Clinical Oncology, 40, 717-721. https://doi.org/10.1093/jjco/hyq061

[23] Bouchardy, C., Rapiti, E., Blagojevic, S., Vlastos, A.T. and Vlastos, G. (2007) Older Female Cancer Patients: Importance, Causes, and Consequences of Undertreatment. Journal of Clinical Oncology: Official Journal of the American Society of Clinical Oncology, 25, 1858-1869. https://doi.org/10.1200/JCO.2006.10.4208

[24] Djordjevic, N., Karanikolic, A. and Pesic, M. (2004) Breast Cancer in Elderly Women. Archives of Gerontology and Geriatrics, 39, 291-299. https://doi.org/10.1016/j.archger.2004.05.002

[25] Giordano, S.H., Hortobagyi, G.N., Kau, S.W., Theriault, R.L. smf Bondy, M.L. (2005) Breast Cancer Treatment Guidelines in Older Women. Journal of Clinical Oncology: Official Journal of the American Society of Clinical Oncology, 23, 783-791. https://doi.org/10.1200/JCO.2005.04.175

[26] Pang, A., Ho, S. and Lee, S.C. (2013) Cancer Physicians' Attitude towards Treatment of the Elderly Cancer Patient in a Developed Asian Country. BMC Geriatrics, 13, 35. https://doi.org/10.1186/1471-2318-13-35

[27] Rocco, N., Rispoli, C., Pagano, G., Ascione, S., Compagna, R., Danzi, M., et al. (2013) Under Treatment of Breast Cancer in the Elderly. BMC Surgery, 13, S26. https://doi.org/10.1186/1471-2482-13-S2-S26

[28] Gajdos, C., Tartter, P.I., Bleiweiss, I.J., Lopchinsky, R.A. and Bernstein, J.L. (2001) The Consequence of Undertreating Breast Cancer in the Elderly. Journal of the American College of Surgeons, 192, 698-707. https://doi.org/10.1016/S1072-7515(01)00832-8

[29] Bouchardy, C., Rapiti, E., Fioretta, G., Laissue, P., Neyroud-Caspar, I., Schafer, P., et al. (2003) Undertreatment Strongly Decreases Prognosis of Breast Cancer in Elderly Women. Journal of Clinical Oncology. Official Journal of the American Society of Clinical Oncology, 21, 3580-3587. https://doi.org/10.1200/JCO.2003.02.046

[30] Siegelmann-Danieli, N., Khandelwal, V., Wood, G.C., Mainali, R., Prichard, J., 
Murphy, T.J., et al. (2006) Breast Cancer in Elderly Women: Outcome as Affected by Age, Tumor Features, Comorbidities, and Treatment Approach. Clinical Breast Cancer, 7, 59-66

[31] Bank, T.W. (2016) Life Expectancy at Birth, Female (Years).

[32] Guth, U., Myrick, M.E., Kandler, C. and Vetter, M. (2013) The Use of Adjuvant Endocrine Breast Cancer Therapy in the Oldest Old. Breast, 22, 863-868. https://doi.org/10.1200/JCO.2003.02.046

[33] Pallis, A.G., Fortpied, C., Wedding, U., Van Nes, M.C., Penninckx, B., Ring, A., et al. (2010) EORTC Elderly Task Force Position Paper: Approach to the Older Cancer Patient. European Journal of Cancer, 46, 1502-1513. https://doi.org/10.1016/j.ejca.2010.02.022

[34] Makary, M.A., Segev, D.L., Pronovost, P.J., Syin, D., Bandeen-Roche, K., Patel, P., et al. (2010) Frailty as a Predictor of Surgical Outcomes in Older Patients. Journal of the American College of Surgeons, 210, 1-8. https://doi.org/10.1016/j.jamcollsurg.2010.01.028

[35] Parks, R.M., Lakshmanan, R., Winterbottom, L., Al Morgan, D., Cox, K. and Cheung, K.L. (2012) Comprehensive Geriatric Assessment for Older Women with Early Breast Cancer-A Systematic Review of literature. World Journal of Surgical Oncology, 10, 88. https://doi.org/10.1186/1477-7819-10-88 